\title{
Trial Blinding Schema
}

National Cancer Institute

\section{Source}

National Cancer Institute. Trial Blinding Schema. NCI Thesaurus. Code C49658.

The name of a code list that contains terms to define the type of blinding that is used for the trial. 